\title{
Clinical and Laboratory Features of Systemic Lupus Erythematosus in pediatric patients at Hue Central Hospital, Vietnam
}

\author{
Nguyen Huu Son*, Nguyen Thi Hong Duc, Nguyen Thi Diem Chi, Nguyen Thi Hoang Anh \\ Pediatric Center, Hue Central hospital
}

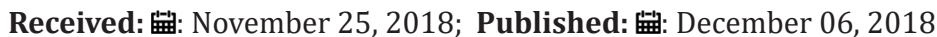

*Corresponding author: Nguyen Huu Son, Pediatric Center, Hue Central Hospital

\begin{abstract}
Objectives: To study the clinical characteristics and laboratory profile of systemic lupus erythematosus (SLE) in pediatric Patients at Hue Central Hospital of Vienam.

Methods: Children presenting to our Pediatric Center with suspected SLE, fulfilling SLICC 2012 criteria for the diagnosis of SLE were reviewed retrospectively. The study period was from January 2017 to October 2018. The clinical presentation, laboratory parameters and histopathology were analyzed.

Results: A total of 21 patients fulfilled the SLICC 2012 criteria; there were 16 girls and 5 boys with a sex ratio of 1:3.2 favoring girls. The mean age on presentation was $13,24 \pm 1.411$ years with a range of 10 - 16 years. The most common symptom was nephrotic damage $76,2 \%$, acute cutaneous lupus 71,4\%; nonscarring alopecia $66,7 \%$, chronic cutaneous, synovitis $42,9 \%$, hemolytic anemia $38,2 \%$, oral or nasal ulcers $23,8 \%$. Anti-dsDNA antibody positivity $85,7 \%$, ANA positivity $81 \%$. Lupus nephritis IV is the most common in $42,9 \%$.

Conclusion: SLE in children has a wide range of presentations and complex progression so that a high index of suspicion should be maintained in order to make an early diagnosis is very necessary.

Keywords: Anemia; Systemic Lupus International Collaborating Clinics; Antinuclear Antibodies; Lupus Nephritis; Systemic Lupus Erythematosus

Abbreviations: SLE: Systemic Lupus Erythematosus; cSLE: Childhood-Onset SLE; ANAs: Antinuclear Antibodies (ANAs); dsDNA: Double-Stranded DNA (dsDNA); LN: Lupus Nephritis
\end{abstract}

\section{Introduction}

Systemiclupus erythematosus(SLE) is an autoimmune condition characterized by multiorgan inflammation and autoantibodies production. The course of this disease is characterized by periods of flare and remission, and inflammation can result in irreversible tissue damage, as well as premature death [1]. The etiology remains poorly understood; however, genetic and environmental factors are involved in the pathogenesis [2]. Ten to twenty percent of cases are diagnosed in the first 2 decades of life with a peak incidence at 1014 years with female predominance, the disease is rare in children below 5 years old $[3,4]$. It has been suggested that children with SLE had different signs and symptoms at onset and a more severe and aggressive disease course than adult patients [5-7]. There is no specific diagnostic test for cSLE, and diagnosis is notoriously difficult due to protean clinical symptoms and signs. The clinical manifestations of SLE have been extensively described from different geographical parts of the word, the prevalence and severity of the disease differs among ethnic groups [8-12]. The disease has variable presentations including conditional symptoms, cutaneous, cardiac, pulmonary, musculoskeletal and renal. The disease course is characterized by periods of remission and flares and children with SLE have more active disease at presentation and over time than do adults with SLE, especially active renal disease [13]. The aim of our retrospective study was to determine the clinical, laboratory characteristics and classification of lupus nephritis of childhood SLE in the center of Vietnam.

\section{Patients and Methods}

We reviewed the hospital records of children younger than 16 years of age who were diagnosed to have SLE at Pediatric Center 
of Hue Central Hospital between January 2016 and October 2018. The diagnosis of SLE was made on the basis of the Systemic Lupus International Collaborating Clinics (SLICC) 2012 criteria [14]. All patients were reviewed retrospectively for demographic characteristics, clinical and laboratory variables.

We recorded the details of clinical signs, symptoms, and the various investigations performed such as complete hemogram, direct Coombs test, $24 \mathrm{~h}$ urinary proteins. In the immunological tests, antinuclear antibodies (ANAs) and antibodies titers to double-stranded DNA (dsDNA) were measured using an indirect immunofluorescence test; ANA titer of more than 1: 40 and an anti-dsDNA antibody level of more than $55 \mathrm{IU} / \mathrm{ml}$ were considered positive. 7 patients underwent renal biopsy. Renal lesions were classified according to the World Health Organization classification (WHO) [15]:

i. Class II: pure mesangiale proliferative LN;

ii. Class III: focal segmental proliferative glomerulonephritis $\mathrm{LN}$;

iii. Class IV: diffuse glomerulonephritis LN and

iv. Class V: diffuse membranous glomerulonephritis LN.

Mixed class IV + class V and class III+ class V was grouped as class IV and class III respectively. A second or even a third renal biopsy was in some cases indicated during the course of the disease. Specific histological features were assessed in each biopsy to give insight into activity and chronicity of lesions. All data were analyzed using IBM SPSS statistics v19, using adequate test and accepting $\mathrm{P}<0.05$.

\section{Results}

Table 1: Clinical manifestations at presentation.

\begin{tabular}{|c|c|c|}
\hline Manifestation & Frequency & Percentage (\%) \\
\hline Acute cutaneous lupus & 15 & 71.4 \\
\hline $\begin{array}{c}\text { Chronic cutaneous } \\
\text { lupus }\end{array}$ & 2 & 9.5 \\
\hline Arthritis & 9 & 42.9 \\
\hline Oral or nosal ulcer & 5 & 23.8 \\
\hline Nonscarring alopecia & 14 & 66.7 \\
\hline Renal disease & 16 & 76.2 \\
\hline Synovitis & 6 & 28.6 \\
\hline Neuropsychiatric & 3 & 14.3 \\
\hline
\end{tabular}

A total of 21 pediatric patients, who fulfilled the SLICC 2012 diagnostic criteria, were included in this study. There were 5 males and 16 females at presentation with a sex ratio of 1:3.2 favoring girls. The average age at diagnosis was $13,24 \pm 1.411$ (range 10 - 16 years). The clinical manifestations of SLE are presented below. Most of these manifestations have been included as part of classification criteria for SLE, as a means of categorizing patients for study purposes. The most common clinical manifestations seen were acute or chronic cutaneous lupus in $81.0 \%$, followed by renal disease in $76.2 \%$, nonscarring alopecia in $66.7 \%$ and arthritis in $42.9 \%$ of patients. Other manifestations are listed in Table 1.
Among hematological manifestations, leukopenia was observed in 1 patients (4.8\%), thrombocytopenia was observed in 3 patients (14.3\%), and hemolytic anemia was observed in 8 patients $(38.2 \%)$ (Table 2). The immunological parameters are show in Table $2.81 \%$ of our patients had positive ANA titer. Anti-ds- DNA was positive in $85.7 \%$ of patients. Among 16 patients with renal disease, 7 of them had renal biopsy with histopathological evaluation classified according to modified world Health Organization classification (Table 3).

Table 2: Laboratory investigations.

\begin{tabular}{|c|c|c|}
\hline Laboratory Investigations & Frequency & Percentage (\%) \\
\hline ANA & 17 & 81 \\
\hline AntidsDNA & 18 & 85.7 \\
\hline Thrombocytopenia & 3 & 14.3 \\
\hline Haemolytic anaemia & 8 & 38.2 \\
\hline Leukopenia & 1 & 4.8 \\
\hline 24-hour urine protein $\geq 0.5 \mathrm{~g}$ & 16 & 76.2 \\
\hline
\end{tabular}

Table 3: Classification of lupus nephritis.

\begin{tabular}{|c|c|c|}
\hline Classification of Lupus Nephritis & Frequency & Percentage (\%) \\
\hline Class III & 2 & 28,6 \\
\hline Class IV & 3 & 42.9 \\
\hline Class V & 1 & 14.3 \\
\hline Class IV-V & 1 & 14.3 \\
\hline
\end{tabular}

\section{Discussion}

This is a retrospective single center study carried out in Pediatric Center of Hue Central Hospital. The total number of SLE patients diagnosed in the period from January 2017 to October 2018 was 21 patients. This small number of patients may be due to that many pediatric SLE patients are followed by adult rheumatologist due to adolescent predilection of this disease. Therefore, Knowledge of general pediatric diseases that can mimic SLE is very important in making the accurate diagnosis. Age at onset ranged from 10-16 year with mean of $13,24 \pm 1.411$ years. In pediatric population, SLE is more common in aldolescent than that in children under 5 years old. Our data was simillar to other studies such as Hiraki with the average of age was 13,2 $\pm 3,17$ years [16], Bader Meunier with the onset age at $11,5 \pm 2,5$ years [17]. According to Jebali et al. [18], about 15 to $20 \%$ of SLE starts in childhood. However, the exact prevalence of cSLE among the SLE population remains unknown.

In Egypt, several studies [19,20] have reported a relatively high prevalence of lupus in Egyptian children compared to Tunisian children. The disease was diagnosed before the age of 10 years in $17 \%$ of patients. The majority of cSLE children were aged above 10 years $[21,22]$. Children with SLE are more susceptible than adults to nephritis $[19,22]$. In Arab countries, pediatric lupus nephritis was noted in 29 to $80 \%$ of cases [9,21]. In western countries, renal involvement was reported also in 30 to $80 \%$ [23]. It affected females more than males and in our population with the female to male ratio was 3.2:1. This was consist to the report of Thabet $Y$ [24]. In study of J Piette and B Wechsles showed that in 85\% SLE patients was female at reproductive age. In the study of Jebali et

Cite this article: Nguyen Huu Son, Nguyen Thi Hong Duc, Nguyen Thi Diem Chi, Nguyen Thi Hoang Anh. Clinical and Laboratory Features of Systemic Lupus Erythematosus in pediatric patients at Hue Central Hospital, Vietnam. Biomed J Sci \& Tech Res 11(5)-2018. BJSTR. MS.ID.002159. DOI: $10.26717 /$ BJSTR.2018.11.002159. 
al. [18] showed that, female to-male ratio was 9.75/1 while in the other reports, there was a lower predilection for female gender in childhood lupus $[25,26]$. The patients with SLE may present with various systemic manifestations. The most common clinical manifestation in our study was neurological damage $76,2 \%$, acute cutaneous lupus 71,4\%; nonscarring alopecia 66,7\%, chronic cutaneous, synovitis $42,9 \%$, hemolytic anemia $38,2 \%$, oral or nasal ulcers $23,8 \%$.

This shows that it is difficult to diagnose SLE based on clinical features only. The clinical diagnosis of SLE hinges on careful and very thorough assessment of the presenting clinical features, examination of all the organ systems and selected investigations. Symptoms often occur intermittently and cumulatively over many months and years. Oral ulcers, arthralgia, hair fall, Raynaud's phenomenon, photosensitive rashes, pleuritic chest pains, headaches, fatigue, fevers and lymphadenopathy are just a few of the many non-specific presenting features of this disease. Clinical examination of all organ systems including routine urinalysis and blood pressure measurement is mandatory. Simple investigations may yield useful information. In the presence of suggestive clinical signs and symptoms, laboratory testing can support and confirm the diagnosis of SLE. A hallmark of SLE is the production of multiple autoantibodies. The commonest autoantibody is the antinuclear antibody (ANA), present in more than $95 \%$ of SLE patients.

In the presence of an ANA, it is appropriate to examine for specific autoantibodies including double-stranded DNA (dsDNA) and the extractable nuclear antigens (ENAs), recognizing that particular autoantibodies correlate with certain disease features [27]. The test for ANA has high sensitivity ( $>95 \%$ ), but its specificity for SLE is as low as $36 \%$ [28]. Moreover, up to $10 \%$ of 'healthy' children will demonstrate a positive ANA. In SLE, anti-dsDNA antibodies have high specificity. In our study, $81 \%$ of our patients had positive ANA titer and Anti-ds- DNA was positive in $85.7 \%$ of patients which is similar to other studies [29]. In our study, The most frequent histopathological finding was class IV LN (42.9\%), approaching the results from several reports, ranging from $37 \%$ to $46 \%[30,31]$. Class $\mathrm{V}$ LN has been reported to have a lower incidence in children [32]. In our group, pure class V LN was found only in $14.3 \%$ of cases.

\section{Conclusion}

In conclusion, lupus nephritis is rare in children. SLE in children has varied clinical and laboratory presentations depending on the major organs involved. Any child with multisystem involvement, prolonged unexplained fever and atypical clinical manifestations should be evaluated for SLE. Renal biopsy can be done in all patients to detect earlier silent involvement, of kidney.

\section{References}

1. Sit JKK, WKY Chan (2018) Risk factors for damage in childhood-onset systemic lupus erythematosus in Asians: a case control study. Pediatr Rheumatol Online J 16(1): 56.

2. Ballestar E, Esteller M, Richardson BC (2006) The epigenetic face of systemic lupus erythematosus. J Immunol 176(12): 7143-7147.
3. Ferreira J, Trindade VC, Espada G, Morel Z, Bonfá E, et al. (2018) Epidemiology and management practices for childhood-onset systemic lupus erythematosus patients: a survey in Latin America. Clin Rheumatol 37(12): 3299-3307.

4. Harry O, Yasin S, Brunner H (2018) Childhood-Onset Systemic Lupus Erythematosus: A Review and Update. J Pediatr 196: 22-30 e2.

5. Brunner HI, Gladman DD, Ibanez D, Urowitz MD, Silverman ED (2008) Difference in disease features between childhood-onset and adult-onset systemic lupus erythematosus. Arthritis Rheum 58(2): 556-562.

6. Font J, Cervera R, Espinosa G, Pallares L, Ramos Casals M, et al. (1998) Systemic lupus erythematosus (SLE) in childhood: analysis of clinical and immunological findings in 34 patients and comparison with SLE characteristics in adults. Ann Rheum Dis 57(8): 456-459.

7. Tucker LB, Menon S, Schaller JG, Isenberg DA (1995) Adult- and childhood-onset systemic lupus erythematosus: a comparison of onset, clinical features, serology, and outcome. Br J Rheumatol 34(9): 866-872.

8. Abdwani R, Rizvi SG, I El Nour (2008) Childhood systemic lupus erythematosus in Sultanate of Oman: demographics and clinical analysis. Lupus 17(7): 683-686.

9. Alsaeid K, Kamal H, Haider MZ, HM Al Enezi, AN Malaviya (2004) Systemic lupus erythematosus in Kuwaiti children: organ system involvement and serological findings. Lupus 13(8): 613-617.

10. Gottlieb BS, NT Ilowite (2006) Systemic lupus erythematosus in children and adolescents. Pediatr Rev 27(9): 323-330.

11. Kumar S, S Nair, L Rajam (2010) Case series of pediatric systemic lupus erythematosus from Kerala: comparison with other Indian series. Int J Rheum Dis 13(4): 391-395.

12. Muzaffer MA, SM Al Mayouf (2011) Clinical and laboratory variables of childhood systemic lupus erythematosus in western province of Saudi Arabia. Rheumatol Int 31(1): 23-26.

13. Brunner HI, R Mina, C Pilkington, Michael W Beresford, Andreas Reiff, et al. (2011) Preliminary criteria for global flares in childhood-onset systemic lupus erythematosus. Arthritis Care Res (Hoboken) 63(9): 1213-1223.

14. Petri M, AM Orbai, GS Alarcon, Gordon C, Merrill JT, etal. (2012) Derivation and validation of the Systemic Lupus International Collaborating Clinics classification criteria for systemic lupus erythematosus. Arthritis Rheum 64(8): 2677-2686.

15. Haas M, A Loupy, C Lefaucheur, Roufosse C, Glotz D, et al. (2018) The Banff 2017 Kidney Meeting Report: Revised diagnostic criteria for chronic active $\mathrm{T}$ cell-mediated rejection, antibody-mediated rejection, and prospects for integrative endpoints for next-generation clinical trials. Am J Transplant 18(2): 293-307.

16. Hiraki LT, SM Benseler, PN Tyrrell, Hebert D, Harvey E, et al. (2008) Clinical and laboratory characteristics and long-term outcome of pediatric systemic lupus erythematosus: a longitudinal study. J Pediatr 152(4): 550-556.

17. Bader Meunier B, JB Armengaud, E Haddad, Salomon R, Deschênes G, et al. (2005) Initial presentation of childhood-onset systemic lupus erythematosus: a French multicenter study. J Pediatr 146(5): 648-653.

18. Jebali H, M Hajji, L Rais, Hamida FB, Beji S, et al. (2017) Clinicopathological findings and outcome of lupus nephritis in Tunisian children: a review of 43 patients. Pan Afr Med J 27: 153.

19. Bakr A (2005) Epidemiology treatment and outcome of childhood systemic lupus erythematosus in Egypt. Pediatr Nephrol 20(8): 10811086.

20. Elmougy A, A Sarhan, A Hammad, El Refaey A, Zedan M, et al. (2015) Lupus nephritis in Egyptian children: a 16-year experience. J Nephrol 28(5): 557-562. 
21. Bahabri S, EA Sabban, A Al Rashed, , Al Mayouf S, Al Mazyed A, et al. (1997) Juvenile systemic lupus erythematosus in 60 Saudi children. Ann Saudi Med 17(6): 612-615.

22. Bogdanovic R, V Nikolic, S Pasic, Dimitrijević J, Lipkovska Marković J, et al. (2004) Lupus nephritis in childhood: a review of 53 patients followed at a single center. Pediatr Nephrol 19(1): 36-44.

23. Barron KS, ED Silverman, J Gonzales, John D Reveille (1993) Clinical, serologic, and immunogenetic studies in childhood-onset systemic lupus erythematosus. Arthritis Rheum 36(3): 348-354.

24. Thabet Y MA, Achour A, Sakly W, Trabelsi A (2014) Systemic Lupus Erythematosus in Children: A Study about 37 Tunisian Cases. J Clin Cell Immunol 5: 192.

25. Batinic D, D Milosevic, M Coric, M Topalović Grković, M Jelušić, et al. (2015) Lupus nephritis in Croatian children: clinicopathologic findings and outcome. Lupus 24(3): 307-314

26. Singh S, B Abujam, A Gupta, Suri D, Rawat A, et al. (2015) Childhood lupus nephritis in a developing country-24 years' single-center experience from North India. Lupus 24(6): 641-617.

27. Jurencak R, M Fritzler, P Tyrrell, Hiraki L, Benseler S, et al. (2009) Autoantibodies in pediatric systemic lupus erythematosus: ethnic

\section{ISSN: 2574-1241}

DOI: $10.26717 / B J S T R .2018 .11 .002159$

Nguyen Huu S, Nguyen Thi Hong D. Biomed J Sci \& Tech Res

(C) (i) This work is licensed under Creative

BY Commons Attribution 4.0 License

Submission Link: https://biomedres.us/submit-manuscript.php grouping, cluster analysis, and clinical correlations. J Rheumatol 36(2): 416-421.

28. Copple SS, AD Sawitzke, AM Wilson, Tebo AE, Hill HR (2011) Enzyme-linked immunosorbent assay screening then indirect immunofluorescence confirmation of antinuclear antibodies: a statistical analysis. Am J Clin Pathol 135(5): 678-684.

29. Hari P, A Bagga, P Mahajan, Dinda A (2009) Outcome of lupus nephritis in Indian children. Lupus 18(4): 348-354.

30. Das Chagas Medeiros MM, MC Bezerra, FN Braga, da Justa Feijão MR Gois AC, et al. (2016) Clinical and immunological aspects and outcome of a Brazilian cohort of 414 patients with systemic lupus erythematosus (SLE): comparison between childhood-onset, adult-onset, and lateonset SLE. Lupus 25(4): 355-363.

31. Srivastava P, B Abujam, R Misra, , A Lawrence, V Agarwal, et al. (2016) Outcome of lupus nephritis in childhood onset SLE in North and Central India: single-centre experience over 25 years. Lupus 25(5): 547-557.

32. Wu JY, KW Yeh, JL Huang (2014) Early predictors of outcomes in pediatric lupus nephritis: focus on proliferative lesions. Semin Arthritis Rheum 43(4): 513-520.

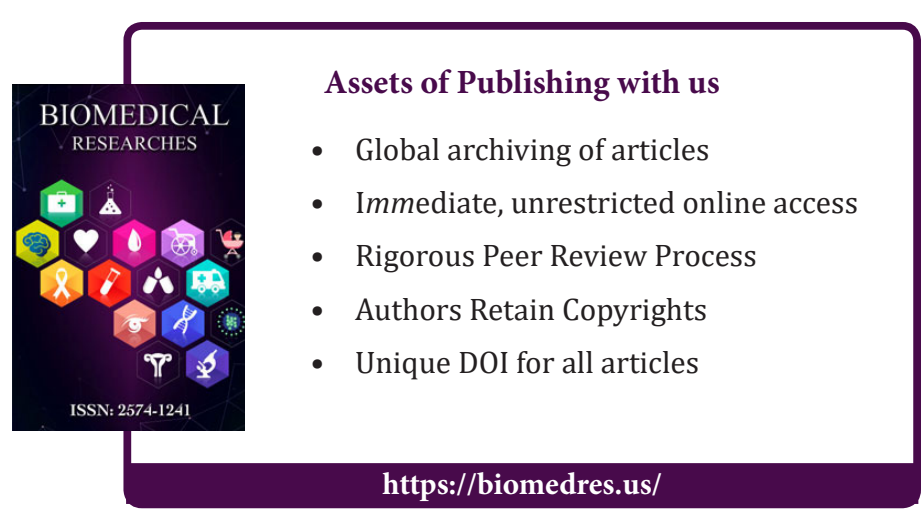

